\title{
A novel dietary improvement strategy: examining the potential impact of community-supported agriculture membership
}

\author{
Angie Vasquez ${ }^{1, *} \uparrow$, Nancy E Sherwood ${ }^{2}$, Nicole Larson $^{3}$ and Mary Story 4 \\ 'Department of Food Science and Nutrition, University of Minnesota, St. Paul, MN, USA: ${ }^{2}$ HealthPartners Institute for \\ Education and Research, Bloomington, MN, USA: ${ }^{3}$ Division of Epidemiology and Community Health, School of \\ Public Health, University of Minnesota, Minneapolis, MN, USA: ${ }^{4}$ Community and Family Medicine and Global \\ Health, Duke University, Durham, NC, USA
}

Submitted 2 September 2015: Final revision received 25 November 2015: Accepted 9 December 2015: First published online 9 February 2016

\begin{abstract}
Objective: To investigate the use of community-supported agriculture (CSA) as an employer-based health promotion intervention.

Design: Quasi-experimental study using a convenience sample of employees at three employers.

Setting: Participants and controls from three Minnesota employers completed baseline and follow-up health assessments and surveys about their experiences with CSA.

Subjects: A total of 324 participants purchased a CSA share and were eligible for study inclusion. Study participants were matched by age, sex, employer and occupation to a non-randomized control group of individuals who did not purchase a CSA share but completed health assessments during the same time frame as the study participants.

Results: The majority of participants were female, white, middle-aged and highly educated. The most common reason for purchasing a CSA share was a desire for fresh food, and the majority of participants were satisfied with their experience. Participants reported a significant increase in the number of vegetables present in the household and the frequency of family meals. The frequency of eating out decreased significantly, especially at fast-food restaurants. Participants also reported an increase in the amount and variety of produce consumed. However, health assessment data did not show significant changes in dietary intake, health status or BMI.

Conclusions: CSA participation was associated with improvement in some aspects of the household environment and dietary behaviours. Further research is needed to determine whether employer-based CSA interventions may also lead to improvements in dietary intake and health.
\end{abstract}

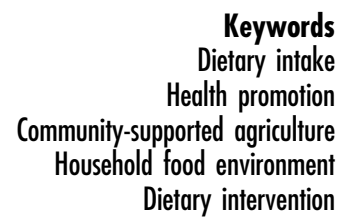

The prevalence of chronic diseases is of major public health concern and places a burden upon society by increasing the rates of premature morbidity and mortality, decreasing productivity and increasing health-care costs. In the USA, half of all adults had one or more chronic disease and one in four adults had two or more chronic diseases as of $2012^{(1,2)}$. Recent estimates indicate that US health expenditures total \$US 2.7 trillion and account for $17.9 \%$ of the Gross Domestic Product ${ }^{(3)}$. An estimated $78 \%$ of these expenditures are attributed to chronic disease $^{(4)}$. Left unchecked, health-care costs are projected to reach \$US 4.6 trillion and to comprise $19.9 \%$ of the Gross Domestic Product by $2022^{(5)}$.

$†$ Current address for correspondence: 4133 Drew Avenue South, Minneapolis, MN 55410, USA.
Worksite health promotion programmes to improve employee health and curb health-care costs are growing in popularity in the USA ${ }^{(6)}$. President Obama's American Recovery and Reinvestment Act of 2009 dedicated \$US 650 million to support health promotion initiatives that target obesity, tobacco and other chronic disease risk factors $^{(7)}$, and the Affordable Care Act of 2010 contains specific provisions to encourage employers to implement health promotion programmes ${ }^{(8)}$. Worksites provide an opportune setting for health promotion given that most adults spend more time at work than anywhere else ${ }^{(9)}$. Additionally, characteristics such a shared purpose and culture, social and organizational support, and robust communication systems can help drive programme adoption and engagement. Worksite health promotion programmes have been demonstrated to positively 
influence health behaviours, biometric measures and financial outcomes ${ }^{(10)}$, but the effects of these programmes are often small to modest ${ }^{(11-13)}$. The current study builds upon the existing research by evaluating the effectiveness of a novel, worksite health promotion intervention designed to improve the dietary intake and health of employees using community-supported agriculture (CSA). Common health promotion interventions include weightloss classes, frequent fitness programmes and farmers' markets, and CSA is a unique variant of such programmes. In addition to being one of the first studies to evaluate the use of CSA as an employer-based intervention, the present study fulfills a gap in the existing literature by evaluating the potential of a worksite health promotion intervention to improve the household food environment and dietary behaviours.

CSA is a form of direct marketing in which consumers and farmers engage in a mutually supportive relationship by sharing in the risks and benefits of food production ${ }^{(14-16)}$. Members purchase a share prior to the start of the growing season and, in return, they receive regular allotments of the farm's harvest throughout the season. The core product offerings are typically fresh vegetables and fruits ${ }^{(17)}$ that are grown utilizing organic or biodynamic farming methods ${ }^{(15,16,18,19)}$. Offering CSA at the worksite is a potentially cost-effective and far-reaching approach to improving employees' access to a variety of fruits and vegetables. Unlike with farmers' markets, grocery stores and other food venues, where individuals can select only those foods with which they are familiar, CSA provides exposure to a variety of foods and typically provides preparation suggestions. The social cognitive theory of behavioural change provides a framework for understanding how CSA might influence dietary intake and health through changes to environmental, personal and behavioural related factors. Changes in the household food environment and meal patterns related to CSA participation have the potential to increase fruit and vegetable intake. Farm newsletters and the cookbook support self-efficacy for participants to use items in the CSA, and the community aspects of CSA reinforce positive dietary behaviour. The key objectives of the present study were to: (i) evaluate employee participants' overall CSA experience; (ii) determine whether healthful changes occur in participants' household food environment and dietary behaviours; and (iii) investigate the association of CSA participation with dietary intake and health outcomes.

\section{Methods}

\section{Study design and population}

The study was conducted by a Minnesota-based health system and included a convenience sample of health system employees and employees of two large government employers located in the Minneapolis/St. Paul metropolitan area of Minnesota, USA. The two government employers were selected due to their large size and contractual relationship with the health system for their employees' health insurance. Participants were recruited using Intranet postings, newsletters and emails. Study eligibility criteria were purchase of a CSA share for the summer of 2009 (June-October), completion of a health assessment (HA) in the year prior to and following the CSA season, and completion of a baseline and follow-up CSA survey.

The HA and CSA surveys were administered online and all data were self-reported. The HA is administered annually as part of the employers' health insurance plan and is typically taken in late autumn or early winter depending on the employer's benefits enrolment schedule. It is used to identify individual- and population-level risks and its validity has been previously demonstrated in multiple studies ${ }^{(20-23)}$. Baseline and follow-up surveys assessed the CSA experience, the household food environment and dietary behaviours. Questions regarding the household food environment were developed using a modified version of the Household Food Inventory checklist, which was based on the previously validated Block Food Frequency Questionnaire ${ }^{(24-27)}$.

A total of 371 participants completed the baseline HA and CSA survey; forty-seven of these participants were lost to follow-up, resulting in 324 participants who completed all study inclusion requirements (Fig. 1). Study participants were matched by age, sex, employer and occupation level to a non-randomized control group of individuals who did not purchase a CSA share but completed HA during the same time frame as participants. For two of the employers, each participant ( $n$ 188) was matched to three controls. The use of controls for the third employer site was not allowed due to contract specifications with the health plan regarding the use of HA data. Participants were matched to three controls to ensure that each participant had at least one control who completed the HA at baseline and follow-up. A total of sixty-one of the matched controls did not complete one or both HA, leaving 503 controls that were included in the study.

\section{Measures}

Sociodemographic and housebold characteristics

Participants and controls self-reported their age, race, ethnicity, occupation and educational level on the baseline HA. Occupation was assessed using the categories of administrative support, labour or production, professional/ management, retired, sales, service, skilled craft, student, technician or other. Educational level was assessed by asking participants to select the highest level of education completed and responses were summarized using three categories (graduate studies, college degree, some college or less). Participants also reported the number of adults and children living in their household. Weight management status was assessed on the CSA survey using a question that 


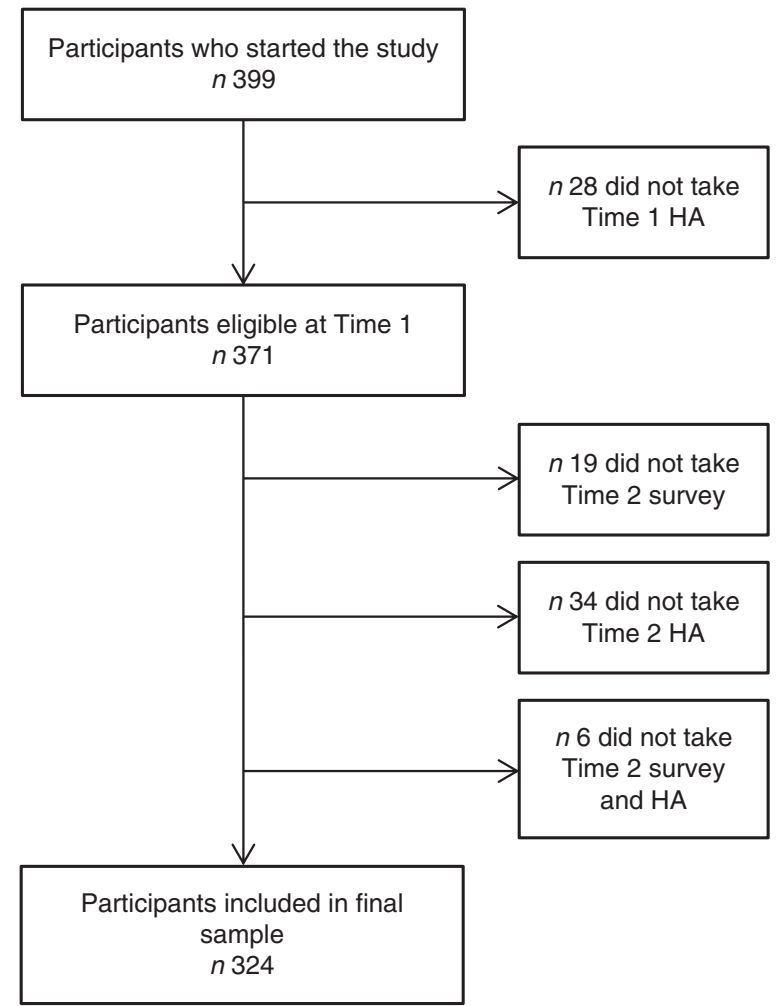

Fig. 1 Flowchart describing participation in the communitysupported agriculture (CSA) study. Time 1 and Time 2 surveys assessed CSA experience, household food environment and dietary behaviours (HA, health assessment)

asked participants whether they were trying to lose weight, maintain weight or gain weight.

\section{Community-supported agriculture experience}

The baseline CSA survey asked participants whether they had ever purchased a CSA share before and their reasons for participating in CSA from a list of fourteen options (e.g. improve health, support small farmers, family experience). The follow-up survey asked participants about their satisfaction with the CSA experience, what they liked about CSA, share utilization and their future plans. Participants ranked their satisfaction (e.g. produce quantity, quality, freshness, variety, convenience of the pick-up site) using a four-point Likert scale. Overall expectations were also assessed, and participants were asked whether they planned to purchase a CSA share next year.

\section{Household food environment and meal patterns}

The baseline and follow-up CSA surveys asked participants to indicate for thirteen different fruits whether they were present, present and visible, or not present - and similarly for twenty-one different vegetables whether they were present or not present - in their household. CSA farm information was reviewed to ensure that response options were reflective of items commonly received in CSA shares and an 'other' category was available for participants to indicate any produce items not listed. Participants reported on household meal frequency (i.e. breakfast, lunch and dinner) during the past $7 \mathrm{~d}$ and responses were summarized to create a total household meal frequency score. Respondents were also asked how many times all or most of their household members planned meals together and the number of times fruits and vegetables were offered at a snack or meal. The total frequency of eating at fast-food, fast casual, casual, full-service and fine dining restaurants combined was evaluated, and fast-food restaurant eating was evaluated separately.

\section{Dietary intake and health outcomes}

The follow-up CSA survey asked participants about whether they thought the amount and variety of produce they consumed had increased, stayed the same or decreased due to CSA participation. The baseline and follow-up HA assessed daily produce servings by asking participants how many fruits and vegetables they consumed on a typical day, with response options ranging from 0 to 11 or more. Weekly produce variety was also assessed on the baseline and follow-up HA by asking participants to indicate the foods they had eaten at least once in the past $7 \mathrm{~d}$ from a subset of twelve food items that were selected from the previously validated Recommended Foods Score ${ }^{(28)}$ based on their relevance to CSA participation. Health status and BMI were self-reported on the HA at baseline and follow-up.

\section{Statistical analyses}

Descriptive statistics were used to evaluate participants' demographic characteristics, reasons for joining, satisfaction, future intentions and self-reported change in produce consumption and variety. Factor analysis was used to categorize the variables regarding the reasons participants joined CSA, satisfaction and aspects participants liked about their CSA experience due to the large number of potentially related response variables (Table 1 ). To determine whether CSA history and weekly share utilization were predictive of participants' future plans for participation, multinomial logistic regression was used. The change in participants' household food environment, meal patterns and restaurant frequency was evaluated using the pairedsamples $t$ test or the Wilcoxon signed-rank test. Multiple linear regression models were used to investigate the association between CSA participation and daily produce servings, weekly produce variety, BMI and health status when compared with matched controls. Multiple linear regression was also used to determine whether weekly CSA share utilization was predictive of participants' change in daily produce servings from baseline to follow-up. Weekly share utilization, daily produce servings, total restaurant frequency and BMI variables were log-transformed due to a skewed distribution. Covariates were included in regression models as described in the Results section for each analysis and included age, sex, educational status, employer, CSA 
Table 1 Factors for reason for joining the CSA, satisfaction and aspects liked about the CSA experience among a convenience sample of employees at three employers in the Minneapolis/ St. Paul metropolitan area of Minnesota, USA

\begin{tabular}{ll}
\hline Factor/variable & $a$ \\
\hline Joined reasont & 0.72 \\
Environment/agriculture & \\
$\quad$ Concern for the environment & \\
Organic food & \\
Support small farmers & \\
$\quad$ Support sustainable agriculture & \\
Support local farmers & \\
Experience/health & \\
Educational experience & \\
Family experience & \\
Improve health & \\
Improve eating habits & \\
Recipes & \\
Satisfaction & \\
Food & \\
Quality & \\
Quantity & \\
Freshness & \\
Variety & \\
Cookbook & \\
Logistics & \\
Pick-up site convenience & \\
Distribution time/day & \\
Window of time for pick-up & \\
Community/farm & \\
Newsletter & \\
Farm community & \\
Farm communication & \\
Farm website & \\
Packaging & \\
Employer communication & \\
Aspects liked about CSA experience & \\
Food/health & \\
Fresh food & \\
Healthy eating & \\
Exposure to new foods & \\
Organic food & \\
Supporting sustainable agriculture \\
Experience & \\
Convenience & \\
Camaraderie with co-workers \\
Educational experience \\
Farm activities \\
Being connected to farm \\
Newsletter \\
$\quad$ Recipes & \\
\hline
\end{tabular}

CSA, community-supported agriculture.

†Fresh food variable excluded because all 324 participants selected this as a reason for joining CSA. Avoid shopping at grocery stores and like to eat in-season variables were excluded due to low eigenvalues.

share type, BMI, health status, readiness to change, reasons joined, satisfaction, daily produce servings, weekly produce variety, liked reasons, sugary food and drink consumption, overall expectations, restaurant frequency, household meal frequency, frequency of servings fruits, CSA price, and change in amount and variety of produce consumed. Inclusion of covariates was based results of bivariate analyses and conceptual relevance to each of the research questions. Analyses were conducted using the statistical software package SAS version 9.3 and a probability level of $0 \cdot 05$ was used to determine statistical significance.

\section{Results}

\section{Sociodemographic and bousebold characteristics}

The results of the sociodemographic analysis are provided in Table 2 and showed that the majority of participants were female, white, middle-aged (mean $=44$ years) and highly educated. Most participants also lived in households with two adults and children. Additionally, a slight majority of participants were overweight or obese. A slight majority of participants also reported that they were trying to lose weight (64.5\%) at baseline, and $29.6 \%$ reported that they were trying to maintain their weight. Comparison of the 188 participants and 503 controls showed that there were no significant differences between groups for demographic variables with the exception of education; a greater proportion of participants $(44.7 \%)$ held a graduate degree compared with controls $(31 \cdot 8 \%)$.

\section{Community-supported agriculture experience}

Table 3 shows the reasons participants selected for joining a CSA, with the most common being fresh food and a desire to avoid shopping at grocery stores. The majority of participants indicated that the CSA experience met or exceeded their expectations, with produce freshness, quality and logistics receiving the highest satisfaction rankings. Although most participants were satisfied with all aspects of their CSA experience, fewer were satisfied with produce quantity and variety than with other aspects of the experience (Table 4). The aspects that participants liked most about their CSA experience included fresh food, healthy eating and supporting sustainable agriculture. In contrast, the family experience, camaraderie with co-workers and newsletter were the least frequently liked aspects of the CSA experience.

Most participants reported high weekly utilization of their CSA share with $59.6 \%$ of respondents using three-quarters or more and another $29.5 \%$ using half to three-quarters of the items received. When asked about their plans to purchase a CSA share again in the following year, 38.4\% indicated that they planned to purchase a share from the same farm and $5.7 \%$ indicated that they planned to purchase a share from a different farm. Approximately one-third of respondents reported that they were unsure of their plans to purchase from the same or a different farm. The reasons participants gave for not planning to participate in CSA the following year are summarized in Table 5. A multinomial logistic regression model was used to understand future plans for CSA participation in the context of an employer-based intervention and to assess the potential for sustained health benefits (Table 6). The model predicted future plans from prior CSA experience and weekly CSA utilization and found that participants with previous CSA experience had a 7.7 greater odds of reporting that they planned to purchase a CSA share in the future than participants without previous CSA experience $(\beta=2 \cdot 04$, Wald $=10 \cdot 28, P<0 \cdot 01)$. Additionally, participants 
Table 2 Baseline demographic characteristics of the convenience sample of employees ( $n$ 324)† at three employers in the Minneapolis/ St. Paul metropolitan area of Minnesota, USA

\begin{tabular}{|c|c|c|}
\hline & $n$ & $\%$ \\
\hline \multicolumn{3}{|l|}{ Sex } \\
\hline Male & 45 & $13 \cdot 9$ \\
\hline Female & 279 & $86 \cdot 1$ \\
\hline \multicolumn{3}{|l|}{ Race } \\
\hline American Indian or Alaska Native & 3 & 0.9 \\
\hline Asian or Pacific Islander & 8 & 2.5 \\
\hline Black or African American & 2 & 0.6 \\
\hline White & 299 & $92 \cdot 3$ \\
\hline Some other race & 3 & 0.9 \\
\hline Choose not to answer & 8 & 2.5 \\
\hline Unknown & 1 & 0.3 \\
\hline \multicolumn{3}{|l|}{ Ethnicity } \\
\hline Hispanic or Latino & 7 & $2 \cdot 2$ \\
\hline Not Hispanic or Latino & 297 & $91 \cdot 7$ \\
\hline Choose not to answer & 20 & $6 \cdot 2$ \\
\hline \multicolumn{3}{|l|}{ Education } \\
\hline 8th grade or less & 1 & 0.3 \\
\hline High school diploma or GED & 6 & 1.9 \\
\hline Technical training or associate degree & 20 & $6 \cdot 2$ \\
\hline Some college & 32 & 9.9 \\
\hline College degree & 125 & $38 \cdot 6$ \\
\hline Graduate studies & 140 & $43 \cdot 2$ \\
\hline \multicolumn{3}{|l|}{ Occupation } \\
\hline Professional/management & 244 & $75 \cdot 3$ \\
\hline Administrative support & 37 & $11 \cdot 4$ \\
\hline Sales & 11 & $3 \cdot 4$ \\
\hline Technician & 7 & $2 \cdot 2$ \\
\hline Service & 7 & $2 \cdot 2$ \\
\hline Skilled craft & 2 & 0.6 \\
\hline Labour or production & 1 & 0.3 \\
\hline Other & 15 & $4 \cdot 6$ \\
\hline \multicolumn{3}{|l|}{ No. of adults in household } \\
\hline 1 & 63 & $19 \cdot 4$ \\
\hline 2 & 230 & $71 \cdot 0$ \\
\hline 3 & 23 & $7 \cdot 1$ \\
\hline 4 & 8 & $2 \cdot 5$ \\
\hline \multicolumn{3}{|l|}{ No. of children in household } \\
\hline 0 & 76 & $35 \cdot 7$ \\
\hline 1 & 62 & $29 \cdot 1$ \\
\hline 2 & 55 & $25 \cdot 8$ \\
\hline 3 & 16 & $7 \cdot 5$ \\
\hline 4 & 3 & 1.4 \\
\hline 5 & 1 & 0.5 \\
\hline \multicolumn{3}{|l|}{ BMI category } \\
\hline Underweight $\left(<18 \cdot 5 \mathrm{~kg} / \mathrm{m}^{2}\right)$ & 2 & 0.6 \\
\hline Normal weight $\left(18.5-24.9 \mathrm{~kg} / \mathrm{m}^{2}\right)$ & 147 & $45 \cdot 4$ \\
\hline Overweight $\left(25.0-29.9 \mathrm{~kg} / \mathrm{m}^{2}\right)$ & 101 & $31 \cdot 2$ \\
\hline Obese $\left(\geq 30.0 \mathrm{~kg} / \mathrm{m}^{2}\right)$ & 74 & $22 \cdot 8$ \\
\hline
\end{tabular}

GED, General Educational Development.

†The sample size for different variables may vary from the total sample size due to missing responses.

who reported higher weekly CSA share utilization were more likely to report that they planned to purchase a CSA share in the future $(\beta=-2 \cdot 34, \mathrm{OR}=0 \cdot 1$, Wald $=10 \cdot 80$, $P<0 \cdot 01$; higher scores equal lower utilization rates).

\section{Housebold food environment and meal patterns}

Table 7 shows the results of changes in the household food environment, meal patterns and restaurant frequency reported by participants prior to and following participation in the worksite CSA programme. There was a significant decrease in the average number of fruits present in the
Table 3 Reasons for joining the CSA among the convenience sample of employees ( $n$ 324)† at three employers in the Minneapolis/ St. Paul metropolitan area of Minnesota, USA

\begin{tabular}{|c|c|c|}
\hline & $n$ & $\%$ \\
\hline \multicolumn{3}{|c|}{ Fresh food } \\
\hline Yes & 319 & $100 \cdot 0$ \\
\hline No & 0 & 0.0 \\
\hline \multicolumn{3}{|c|}{ Dislike grocery store } \\
\hline Yes & 304 & 93.8 \\
\hline No & 20 & $6 \cdot 2$ \\
\hline \multicolumn{3}{|c|}{ Educational experience } \\
\hline Yes & 261 & 80.6 \\
\hline No & 63 & $19 \cdot 4$ \\
\hline \multicolumn{3}{|c|}{ Family experience } \\
\hline Yes & 226 & $69 \cdot 8$ \\
\hline No & 98 & $30 \cdot 3$ \\
\hline \multicolumn{3}{|c|}{ Recipes } \\
\hline Yes & 219 & $67 \cdot 6$ \\
\hline No & 105 & 32.4 \\
\hline \multicolumn{3}{|c|}{ Concern for the environment } \\
\hline Yes & 179 & $55 \cdot 3$ \\
\hline No & 145 & 44.8 \\
\hline \multicolumn{3}{|c|}{ Improve health } \\
\hline Yes & 137 & $42 \cdot 3$ \\
\hline No & 187 & $57 \cdot 7$ \\
\hline \multicolumn{3}{|c|}{ Organic food } \\
\hline Yes & 134 & 41.4 \\
\hline No & 190 & $58 \cdot 6$ \\
\hline \multicolumn{3}{|c|}{ Support sustainable agriculture } \\
\hline Yes & 112 & $34 \cdot 6$ \\
\hline No & 212 & 65.4 \\
\hline \multicolumn{3}{|c|}{ Desire to eat produce in season } \\
\hline Yes & 91 & $28 \cdot 1$ \\
\hline No & 233 & 71.9 \\
\hline \multicolumn{3}{|c|}{ Improve eating habits } \\
\hline Yes & 85 & $26 \cdot 2$ \\
\hline No & 239 & $73 \cdot 8$ \\
\hline \multicolumn{3}{|c|}{ Support small farmers } \\
\hline Yes & 81 & $25 \cdot 0$ \\
\hline No & 243 & 75.0 \\
\hline \multicolumn{3}{|c|}{ Support local farmers } \\
\hline Yes & 50 & $15 \cdot 4$ \\
\hline No & 274 & 84.6 \\
\hline
\end{tabular}

CSA, community-supported agriculture.

†The sample size for different variables may vary from the total sample size due to missing responses.

household from baseline to follow-up, whereas the change in the number of fruits present and visible from baseline to follow-up was not significant. Participant reports of the number of vegetables present also showed a significant increase from baseline to follow-up. The frequency with which participants served fruits and vegetables at snacks or meals as well as the frequency of family meals increased from baseline to follow-up. Participants' frequency of eating at all restaurant types decreased from baseline to follow-up. Independent-samples $t$ tests were also used to determine whether there were significant differences in results based on participants' weight management status at baseline, with the only difference being the frequency of serving vegetables at snacks or meals. Participants who were trying to lose weight at baseline reported a greater increase in the number of vegetables they served (mean $=0 \cdot 62, \mathrm{SD}=1 \cdot 21)$ than those who were not trying to lose weight (mean $=0 \cdot 24$, $\mathrm{SD}=1 \cdot 22, t(230)=2 \cdot 67, P<0 \cdot 008)$. 
Table 4 Satisfaction with the CSA among the convenience sample of employees ( $n$ 324) $\dagger$ at three employers in the Minneapolis/ St. Paul metropolitan area of Minnesota, USA

\begin{tabular}{|c|c|c|}
\hline & $n$ & $\%$ \\
\hline \multicolumn{3}{|l|}{ Pick-up site } \\
\hline Very satisfied & 267 & 83.7 \\
\hline Satisfied & 44 & $13 \cdot 8$ \\
\hline Unsatisfied & 6 & 1.9 \\
\hline Not applicable & 2 & 0.6 \\
\hline \multicolumn{3}{|l|}{ Quantity } \\
\hline Very satisfied & 153 & 48.0 \\
\hline Satisfied & 103 & $32 \cdot 3$ \\
\hline Unsatisfied & 49 & $15 \cdot 4$ \\
\hline Very unsatisfied & 14 & 4.4 \\
\hline \multicolumn{3}{|l|}{ Quality } \\
\hline Very satisfied & 195 & $61 \cdot 1$ \\
\hline Satisfied & 103 & $32 \cdot 3$ \\
\hline Unsatisfied & 19 & $6 \cdot 0$ \\
\hline Very unsatisfied & 2 & 0.6 \\
\hline \multicolumn{3}{|l|}{ Freshness } \\
\hline Very satisfied & 223 & 69.9 \\
\hline Satisfied & 81 & 25.4 \\
\hline Unsatisfied & 13 & $4 \cdot 1$ \\
\hline Very unsatisfied & 2 & 0.6 \\
\hline \multicolumn{3}{|l|}{ Variety } \\
\hline Very satisfied & 104 & $32 \cdot 6$ \\
\hline Satisfied & 146 & 45.8 \\
\hline Unsatisfied & 62 & 19.4 \\
\hline Very unsatisfied & 7 & $2 \cdot 2$ \\
\hline \multicolumn{3}{|c|}{ Distribution time of day } \\
\hline Very satisfied & 220 & $69 \cdot 0$ \\
\hline Satisfied & 81 & 25.4 \\
\hline Unsatisfied & 11 & 3.5 \\
\hline Very unsatisfied & 5 & 1.6 \\
\hline Not applicable & 2 & 0.6 \\
\hline \multicolumn{3}{|c|}{ Window of time for pick-up } \\
\hline Very satisfied & 225 & $70 \cdot 5$ \\
\hline Satisfied & 75 & 23.5 \\
\hline Unsatisfied & 15 & 4.7 \\
\hline Very unsatisfied & 1 & 0.3 \\
\hline Not applicable & 3 & 0.9 \\
\hline \multicolumn{3}{|l|}{ Quality of newsletter } \\
\hline Very satisfied & 176 & $55 \cdot 2$ \\
\hline Satisfied & 98 & 30.7 \\
\hline Unsatisfied & 24 & 7.5 \\
\hline Very unsatisfied & 3 & 0.9 \\
\hline Not applicable & 18 & $5 \cdot 6$ \\
\hline \multicolumn{3}{|l|}{ Farm community } \\
\hline Very satisfied & 90 & 28.2 \\
\hline Satisfied & 90 & 28.2 \\
\hline Unsatisfied & 14 & 4.4 \\
\hline Very unsatisfied & 5 & 1.6 \\
\hline Not applicable & 120 & 37.6 \\
\hline \multicolumn{3}{|c|}{ Farm communication } \\
\hline Very satisfied & 110 & 34.5 \\
\hline Satisfied & 98 & $30 \cdot 7$ \\
\hline Unsatisfied & 14 & 4.4 \\
\hline Very unsatisfied & 3 & 0.9 \\
\hline Not applicable & 94 & 29.5 \\
\hline \multicolumn{3}{|c|}{ Quality of farm website } \\
\hline Very satisfied & 111 & 34.8 \\
\hline Satisfied & 109 & 34.2 \\
\hline Unsatisfied & 17 & $5 \cdot 3$ \\
\hline Very unsatisfied & 6 & 1.9 \\
\hline Not applicable & 76 & 23.8 \\
\hline \multicolumn{3}{|c|}{ Packaging of produce } \\
\hline Very satisfied & 152 & 47.7 \\
\hline Satisfied & 137 & 43.0 \\
\hline Unsatisfied & 21 & $6 \cdot 6$ \\
\hline Very unsatisfied & 3 & 0.9 \\
\hline Not applicable & 6 & 1.9 \\
\hline
\end{tabular}

Table 4 Continued

\begin{tabular}{|c|c|c|}
\hline & $n$ & $\%$ \\
\hline \multicolumn{3}{|l|}{ Employer communications } \\
\hline Very satisfied & 126 & 39.5 \\
\hline Satisfied & 129 & $40 \cdot 4$ \\
\hline Unsatisfied & 17 & $5 \cdot 3$ \\
\hline Not applicable & 47 & 14.7 \\
\hline \multicolumn{3}{|l|}{ Cookbook } \\
\hline Very satisfied & 172 & 53.9 \\
\hline Satisfied & 120 & 37.6 \\
\hline Unsatisfied & 12 & 3.8 \\
\hline Very unsatisfied & 6 & 1.9 \\
\hline Not applicable & 9 & $2 \cdot 8$ \\
\hline \multicolumn{3}{|l|}{ Price } \\
\hline Too high & 88 & $27 \cdot 7$ \\
\hline About right & 228 & 71.7 \\
\hline Too low & 2 & 0.6 \\
\hline \multicolumn{3}{|l|}{ Overall expectations } \\
\hline CSA experience exceeded my expectations & 100 & 31.5 \\
\hline CSA experience matched my expectations & 142 & 44.7 \\
\hline CSA experience fell short of my expectations & 67 & 21.1 \\
\hline I had no expectations & 9 & $2 \cdot 8$ \\
\hline
\end{tabular}

CSA, community-supported agriculture.

†The sample size for different variables may vary from the total sample size due to missing responses.

\section{Dietary intake and bealth outcomes}

The majority of participants reported the amount (71.5\%) and variety $(87.5 \%)$ of the produce they consumed increased as a result of CSA participation and there was no significant difference in results based on participants' weight management status at baseline. However, daily produce servings as reported on the HA did not show CSA participation to be predictive of the change in dietary intake in models that included matched controls $\left(F(9,681)=0 \cdot 77, P=0.643, R^{2}=-0.003\right)$. Similarly, CSA participation was not found to be predictive of the change in weekly produce variety $(F(9,674)=1.63, P=0.10$, $\left.R^{2}=0.008\right)$. Models used for these analyses controlled for age, sex, educational status, and sugary food and drink consumption. CSA participation was also not predictive of BMI change $\left(F(9, \quad 674)=0.64, \quad P=0.76, \quad R^{2}=-0.005\right)$ or perceived health status $(F(9,674)=1.75, P=0.08$, $\left.R^{2}=0.010\right)$. Covariates in these models included age, sex, educational status, daily produce servings, weekly produce variety, health status, BMI, and sugary food and drink consumption. Weekly CSA share utilization was not predictive of the change in daily produce servings $\left(F(9,205)=0.85, P=0.57, R^{2}=0.040\right)$. This model controlled for BMI, weekly produce variety, readiness to change, the household presence of vegetables, frequency of serving fruits, household meal frequency, restaurant frequency and consumption of sugary foods and beverages.

\section{Discussion}

The current study evaluated the effectiveness of using CSA as an employer-based health promotion intervention. 
Table 5 Reasons for not purchasing a CSA share in the future among the convenience sample of employees ( $n$ 324) at three employers in the Minneapolis/St. Paul metropolitan area of Minnesota, USA

\begin{tabular}{|c|c|c|}
\hline & $n$ & $\%$ \\
\hline \multicolumn{3}{|c|}{ Prefer farmers' market } \\
\hline Yes & 120 & $37 \cdot 0$ \\
\hline No & 204 & 63.0 \\
\hline \multicolumn{3}{|c|}{ Not worth cost } \\
\hline Yes & 68 & $21 \cdot 0$ \\
\hline No & 256 & $79 \cdot 0$ \\
\hline \multicolumn{3}{|c|}{ Prefer grocery store } \\
\hline Yes & 61 & $18 \cdot 8$ \\
\hline No & 263 & $81 \cdot 2$ \\
\hline \multicolumn{3}{|c|}{ Too little variety } \\
\hline Yes & 50 & $15 \cdot 4$ \\
\hline No & 274 & 84.6 \\
\hline \multicolumn{3}{|c|}{ Too much produce } \\
\hline Yes & 44 & $13 \cdot 6$ \\
\hline No & 280 & $86 \cdot 4$ \\
\hline \multicolumn{3}{|c|}{ Planning on growing own produce } \\
\hline Yes & 41 & $12 \cdot 7$ \\
\hline No & 283 & 87.4 \\
\hline \multicolumn{3}{|c|}{ Too little produce } \\
\hline Yes & 37 & 11.4 \\
\hline No & 287 & 88.6 \\
\hline \multicolumn{3}{|c|}{ Personal financial situation } \\
\hline Yes & 27 & $8 \cdot 3$ \\
\hline No & 297 & 91.7 \\
\hline \multicolumn{3}{|c|}{ Dissatisfied with quality } \\
\hline Yes & 25 & $7 \cdot 7$ \\
\hline No & 299 & $92 \cdot 3$ \\
\hline \multicolumn{3}{|c|}{ Household issues } \\
\hline Yes & 19 & 5.9 \\
\hline No & 305 & 94.1 \\
\hline \multicolumn{3}{|c|}{ Inconvenient pick-up } \\
\hline Yes & 16 & 4.9 \\
\hline No & 308 & $95 \cdot 1$ \\
\hline
\end{tabular}

CSA, community-supported agriculture.
Participants had similar demographic characteristics to CSA members in previous studies. A desire for fresh food was the most common reason for purchasing a CSA share, and the majority of participants were satisfied with their experience. Participants also reported a significant increase in the number of vegetables present in the household and family meals, whereas the frequency of eating at restaurants decreased. There were no significant changes in dietary intake and health status compared with controls. The results showed that CSA is a valuable tool for improving the household food environment and dietary behaviours, but further research is needed to determine whether these changes can lead to improvements in dietary intake and health outcomes.

It was hypothesized that an employer-based CSA intervention might expand the reach of CSA to involve more demographically diverse participants, but the results were generally not supportive. Consistent with previous research $^{(14,16,17,19,29-38)}$, the demographic profile of CSA participants was relatively homogeneous. One notable exception is that participants in the present study reported slightly lower education levels than those in previous studies. For example, a study by MacMillan et al. found that $88.5 \%$ of participants completed a bachelor's or graduate degree in comparison to $71.5 \%$ of members in the present study ${ }^{(35)}$. Although this is a small difference from previous studies, these results lend some support to the idea that an employer-based intervention might expand the reach of CSA to a broader demographic. Replication of the intervention in different regions and industries might also attract a more diverse population of

Table 6 Multinomial logistic regression predicting future farm intentions from CSA utilization and history† among the convenience sample of employees at three employers in the Minneapolis/St. Paul metropolitan area of Minnesota, USA

\begin{tabular}{|c|c|c|c|c|}
\hline & \multicolumn{2}{|c|}{ Unsure } & \multicolumn{2}{|c|}{ Yes } \\
\hline & OR & $95 \% \mathrm{Cl}$ & OR & $95 \% \mathrm{Cl}$ \\
\hline CSA utilization & 0.93 & $0.36,2.44$ & $0 \cdot 10^{\star *}$ & $0.02,0.39$ \\
\hline CSA history & 1.60 & $0.52,4.66$ & $7 \cdot 70^{* *}$ & $2 \cdot 21,26 \cdot 82$ \\
\hline CSA matched expectations & $1 \cdot 22$ & $0.52,2.89$ & 1.43 & $0.36,5.63$ \\
\hline CSA exceeded expectations & $1 \cdot 78$ & $0.49,6.39$ & $13 \cdot 93^{\star \star}$ & $2.63,73.83$ \\
\hline CSA price & 0.79 & $0.37,1.68$ & $4 \cdot 23^{\star}$ & $1 \cdot 22,14 \cdot 71$ \\
\hline CSA share type (whole share $v$. less than half share) & 1.64 & $0.58,4.61$ & 1.47 & $0.38,5 \cdot 75$ \\
\hline CSA share type (half share $v$. less than half share) & 2.06 & $0.95,4.47$ & $2 \cdot 00$ & $0.70,5.63$ \\
\hline Employer (employer 1 v. employer 3) & $1 \cdot 18$ & $0.44,3 \cdot 13$ & $2 \cdot 60$ & $0.74,9 \cdot 17$ \\
\hline Employer (employer 2 v. employer 3) & $3 \cdot 90^{\star \star \star}$ & $1 \cdot 76,8 \cdot 66$ & $7 \cdot 10^{\star \star \star}$ & $2.55,19.81$ \\
\hline Change in amount of produce consumed & 1.06 & $0.52,2.18$ & $2 \cdot 22$ & $0.78,6.38$ \\
\hline Change in variety of produce consumed & 1.65 & $0.64,4 \cdot 24$ & $5 \cdot 77^{*}$ & $1 \cdot 17,28.41$ \\
\hline Education (college degree $v$. some college or less) & 0.69 & $0.30,1.57$ & 0.92 & $0.28,3.03$ \\
\hline Education (graduate studies $v$. some college or less) & 1.65 & $0.69,3.93$ & 3.45 & $0.98,12 \cdot 16$ \\
\hline Join reason - environment or agricultural & $1 \cdot 13$ & $0.90,1.42$ & 1.01 & $0.75,1.37$ \\
\hline Join reason - experience or health & 1.02 & $0.80,1.29$ & $0.87^{*}$ & $0.63,1.20$ \\
\hline Liked reason - food or health & $1 \cdot 28$ & $0.93,1.77$ & 1.47 & $0.88,2.43$ \\
\hline Liked reason - experience & 0.97 & $0.78,1.20$ & $1 \cdot 39^{*}$ & $1.06,1.83$ \\
\hline Satisfaction - food & $1 \cdot 30^{\star *}$ & $1.08,1.55$ & $1 \cdot 45^{\star \star}$ & $1 \cdot 13,1.87$ \\
\hline Satisfaction - logistics & $1 \cdot 12$ & $0.89,1.40$ & 0.94 & $0.68,1.30$ \\
\hline Satisfaction - community and farm & 0.95 & $0.88,1.02$ & 0.92 & $0.83,1.01$ \\
\hline
\end{tabular}

CSA, community-supported agriculture.

${ }^{\star} P<0.05,{ }^{\star *} P<0.01,{ }^{\star \star \star} P<0.001$

$+X^{2}(40)=236.04, P<0.001, R^{2}=0.526$. 
Table 7 Household food environment† before and after the employer-based CSA health promotion intervention among the convenience sample of employees ( $n$ 324) at three employers in the Minneapolis/St. Paul metropolitan area of Minnesota, USA

\begin{tabular}{|c|c|c|c|c|c|c|c|c|}
\hline & \multicolumn{3}{|c|}{ Baseline } & \multicolumn{3}{|c|}{ Follow-up } & \multirow[b]{2}{*}{$t$} & \multirow[b]{2}{*}{$P$} \\
\hline & $n$ & Mean & SD & $n$ & Mean & SD & & \\
\hline No. of fruits present in household & 324 & 3.58 & $2 \cdot 12$ & 318 & 3.08 & $2 \cdot 23$ & 3.69 & $<0.01$ \\
\hline No. of fruits present and visible in household & 324 & $2 \cdot 38$ & 1.88 & 318 & $2 \cdot 38$ & 2.02 & 0.11 & 0.91 \\
\hline No. of fruits present or present and visible in household & 324 & 8.34 & $3 \cdot 26$ & 318 & 8.79 & 3.69 & $2 \cdot 36$ & 0.02 \\
\hline No. of vegetables present in household & 324 & 11.52 & 3.30 & 318 & 12.52 & 3.41 & $6 \cdot 29$ & $<0.01$ \\
\hline Frequency fruits typically served at snacks or meals & 324 & 4.91 & 1.38 & 318 & $5 \cdot 20$ & 1.40 & 3.67 & $<0.01$ \\
\hline Frequency vegetables typically served at snacks or meals & 324 & $5 \cdot 26$ & 1.20 & 318 & 5.75 & 1.25 & 7.04 & $<0.01$ \\
\hline Frequency of household meals in past $7 \mathrm{~d} \neq$ & 277 & 8.54 & 3.87 & 274 & 8.98 & 4.25 & 2.07 & 0.04 \\
\hline Frequency of household planning meals in past $7 \mathrm{~d} \S$ & 277 & $2 \cdot 39$ & 1.96 & 272 & $2 \cdot 50$ & $2 \cdot 15$ & 414.5 & 0.37 \\
\hline Frequency of eating at all restaurant types in past $7 d$ & 324 & 2.65 & 1.83 & 318 & $2 \cdot 21$ & 1.82 & $-3248 \cdot 0$ & $<0.01$ \\
\hline Frequency of eating at fast-food restaurants in past $7 \mathrm{~d}$ & 324 & 1.56 & 0.75 & 318 & 1.37 & 0.63 & -1503.5 & $<0.01$ \\
\hline
\end{tabular}

CSA, community-supported agriculture.

†Paired-samples $t$ tests were used in all analyses with the exception of the frequency of household members planning meals together, restaurant eating and fast-food restaurant eating, for which the Wilcoxon signed-rank test was used. In these latter analyses, the signed-rank test statistic is illustrated.

¥Household meal frequency includes the number of times all or most of the participants' household members ate breakfast, lunch or dinner together. $\S$ Household planning meals includes the number of times all or most of the participants' household members planned meals together.

participants. This is important in that expanding the reach of CSA might help target populations who are at high risk for chronic disease such as minorities or individuals of lower socio-economic status. One possible explanation for the lack of diversity among CSA members is the pre-payment of membership fees that is typically required, which might preclude individuals of lower socioeconomic status from participation. A small number of interventions provided financial support for CSA participation to low-income and underserved households and found that participants experienced many of the same benefits as those reported in other studies ${ }^{(33,39)}$.

Participants' motivations for joining CSA were similar to those of members in previous studies with a few notable exceptions $^{(17,19,29,31-33,37,40-44)}$. The majority of CSA members in previous studies reported a desire to support local farmers as a reason for joining CSA ${ }^{(16,31,37)}$ whereas this was not a frequently cited reason for joining in the present study. For example, almost all CSA members (94.8\%) in a study by Landis et al. selected support for local farms as a reason for joining ${ }^{(31)}$, and another study by Cooley and Lass found that $97 \%$ of participants cited support for local farming as a reason for joining ${ }^{(45)}$. Employee participants' focus on the health-related aspects of CSA might be explained by the fact that the CSA programme was part of their employers' wellness programmes. As such, employers' marketing of the CSA programme might have focused on the health benefits of CSA rather than on the environmental and community benefits.

As expected, participants were very satisfied overall, but opportunities were identified for improving certain aspects of the CSA experience. Satisfaction related to logistics was even higher than in previous research, which is not surprising given that CSA shares were delivered to employees' worksites. One of the most common reasons study participants cited for joining a CSA - fresh food - was also one of the aspects they liked most about the CSA experience. In contrast, the family and educational experience were less frequently indicated as aspects of the CSA experience that participants liked despite being among the most common reasons for joining CSA.

Less than half of the study participants planned to renew their CSA membership the following year despite high levels of satisfaction with their experience. Another third of the participants reported that they were unsure of their plans for the following year. These renewal rates are somewhat less than reported in previous studies ${ }^{(16,34,37)}$. However, not all previous studies included 'unsure' as a response category, making direct comparison of results difficult $^{(16,34,37)}$. The one study that included 'unsure' as a response category reported that $60 \%$ of respondents had plans to renew, but only $18 \%$ were unsure, so the actual discrepancy in renewal rates might be less than reported depending on what unsure members decide. The lower renewal rates in the present study might partially be explained by the fact that the majority of participants were first-time CSA members and previous research has shown that first-time members are less likely to renew their membership than those with previous CSA experience $^{(16,19,37)}$. Not surprisingly, participants who utilized more of the food received in their CSA share were more likely to report plans to renew their membership. Participants who reported an increase in the variety of produce they consumed during the CSA season were also more likely to report plans to renew their membership. This is promising in that one of the key objectives of the present intervention was to increase the variety of produce consumption. It suggests that an employer-based CSA intervention could help support sustained rather than just short-term changes in dietary intake given that those employees who reported an increase in produce variety were also more likely to continue CSA participation in the future. 
As expected, there was a significant increase in the amount and variety of vegetables present in the household. It was also expected that the number of fruits present and present and visible would increase given that CSA shares are comprised primarily of produce, but this was not the case. This is likely due to the fact that the geographic region of the study is unsuitable for growing many varieties of fruit crops (e.g. citrus, stone fruits). Of the thirty-one different summer crops grown by the most frequently used farm in the present study, only four of the crops were fruit. It is possible that participants relied primarily on the CSA for their household produce rather than supplementing with other produce items, which could provide some explanation for the fact that fruits present and present and visible did not increase from baseline to follow-up. Also, the increase in the number of vegetables present in the household might have displaced fruits that participants typically keep in the house. Seasonality and the availability of specific produce items might also have been a factor.

The present results showed, as hypothesized, that CSA participation was associated with an improvement in meal patterns and that it also has the potential to improve the dietary patterns of household members. The fact that CSA participants increased the frequency of household meals is important given that previous research has demonstrated an association between family meals and healthy dietary behaviours ${ }^{(46)}$. The frequency of serving fruits and vegetables at snacks or meals also increased despite the decrease in the presence of household fruits. Perhaps CSA participation resulted in a greater focus on incorporating produce into the diet and, as such, fruits were served more often despite the fact that there was not a significant increase in their household availability. The reduction in participants' frequency of eating at all types of restaurant and fast-food restaurants specifically also supports the hypothesis that CSA participation has the potential to improve dietary intake given that restaurant eating has been associated with higher energy intake, higher fat intake and increased body weight ${ }^{(47-50)}$. These results are consistent with anecdotal reports from CSA members in previous studies regarding restaurant eating ${ }^{(34,37)}$.

As hypothesized, study participants' responses to the follow-up CSA survey questions regarding dietary intake indicated that they felt they had increased the amount and variety of produce consumed as a result of CSA participation, which is consistent with previous research ${ }^{(16,35,37)}$. Surprisingly, CSA participation was not associated with an increase in participants' daily produce servings or weekly produce variety as reported in response to the HA survey. One possible explanation for this is that there was a significant time delay between completion of the CSA season and administration of the HA survey. The questions that assessed weekly produce variety were also limited to a select number of produce items and did not include an 'other' category, potentially affecting the accuracy of results. BMI and health status were also measured via the HA and the delayed administration of the HA might explain the lack of significant change in these variables from baseline to follow-up. Additionally, if there were healthy changes in dietary intake associated with CSA participation, these changes might not have been large enough or sustained for a long enough time period to affect BMI and health status.

The current study builds upon previous research by being the first to evaluate the use of CSA as an employerbased health promotion intervention. Previous research has not evaluated associations between CSA participation and meal patterns, the household food environment, dietary intake and health outcomes by quantitatively measuring these variables at baseline and follow-up. The current study also builds upon the existing literature by examining demographic factors and the CSA experience in the context of an employer-based intervention. Limitations of the study include the fact that it was not a randomized trial. Funding limitations also precluded the intervention from being tested in other geographic areas and limited the number of employers that could be included. As such, some findings may not be generalizable to other regions or industries. Additionally, participants were not provided any support or financial incentive for purchasing a CSA share, which could have precluded some socio-economic groups from participating. Participants' knowledge regarding food preparation and cooking practices might have had an effect on dietary change and health outcomes. Farm newsletters and recipes were provided to help participants increase their knowledge, but selfefficacy was not was not directly assessed in the study. The delay in HA administration and design of questions regarding weekly dietary variety are also important limitations. Lastly, the self-report nature of the HA and surveys might have impacted the accuracy of results. A systematic review of the literature conducted by Gorber et al. comparing direct with self-reported measures found that BMI is commonly under-reported ${ }^{(51)}$.

\section{Conclusion}

The present study provides support for the use of CSA as an employer health promotion intervention and provides a foundation for future research in this area. The findings showed that CSA participation is associated with improvements in the household food environment, frequency that produce is served at snacks and meals, frequency of household meals and frequency of restaurant eating. Results regarding the association between CSA participation and dietary intake and health were less definitive. Although participants indicated that they felt the amount and variety of produce they consumed had increased as a result of CSA participation, comparisons 
with matched controls did not yield significant findings. Opportunities for future research include interventions in different regions and industries, improvements in data collection methods, interventions that investigate the use of financial incentives to offset the cost of CSA shares, and interventions that explore complementary support (e.g. education, family activities) to enhance the benefits of CSA participation. Studies that further explore the association between CSA share utilization and outcomes such as the change in household food environment, meal patterns, dietary intake and health outcomes would also be useful. Additionally, studies that directly measure anthropometric and other clinical measures (e.g. BMI, blood pressure, cholesterol) would be helpful in understanding the potential of CSA to improve health outcomes.

\section{Acknowledgements}

Acknowledgements: Data for this research were from the Local Food/Local Health Renewed study, which was conducted by the HealthPartners Institute for Education and Research in collaboration with the State of Minnesota and Hennepin County. Support was provided by study team members Dr Marcus Thygeson, Scott Aebischer and Dawn Barker from HealthPartners; Paul Hungunin from the Minnesota Grown Program; and Linda Feltes from Minnesota Management and Budget. Dr Rich MacLehose provided statistical support and Dr Jamie Stang provided input regarding study findings and interpretation. Financial support: This work was supported by the HealthPartners Research Foundation Partnership Grant (grant number 08-092). In-kind support was provided by Minnesota Management and Budget (MMB) and the Minnesota Department of Agriculture (MDA). The HealthPartners Research Foundation, MMB and MDA had no role in the design, analysis or writing of this article. Conflict of interest: None. Authorship: A.V. drafted the manuscript and conducted the statistical analysis. N.E.S. was the principal investigator and formulated the research questions. All authors contributed to the interpretation of results and manuscript reviews. Ethics of human subject participation: This study was conducted according to the guidelines laid down in the Declaration of Helsinki and all procedures involving human subjects were approved by the HealthPartners Institutional Review Board. Written informed consent was obtained from all participants.

\section{References}

1. Centers for Disease Control and Prevention (n.d.) Chronic disease and health promotion. http://www.cdc.gov/chronic disease/overview/index.htm (accessed November 2012).

2. Ward BW, Schiller JS \& Goodman RA (2014) Multiple chronic conditions among US adults: a 2012 update. Prev Chronic Dis 11, E62.
3. Centers for Medicare \& Medicaid Services (2012) National health expenditure data. http://www.cms.gov/ResearchStatistics-Data-and-Systems/Statistics-Trends-and-Reports/ NationalHealthExpendData/NationalHealthAccountsHistorical. html (accessed April 2012).

4. Anderson G (2004) Chronic conditions: making the case for ongoing care. http://www.partnershipforsolutions.org/DMS/ files/chronicbook2004.pdf (accessed January 2013).

5. Centers for Medicare \& Medicaid Services (2010) National health expenditure projections 2010-2020. https://www.cms. gov/Research-Statistics-Data-and-Systems/Statistics-Trends-andReports/NationalHealthExpendData/downloads/proj2010.pdf (accessed November 2012).

6. Buck Consultants (2009) Working well: a global survey of health promotion and workplace wellness strategies. https://www.worldatwork.org/waw/adimLink?id=363092009 (accessed November 2012).

7. New York Times (2009) Obama's speech on health care reform. http://www.nytimes.com/2009/06/15/health/policy/ 15obama.text.html?pagewanted=all (accessed November 2012).

8. Goetzel RZ, Pei X, Tabrizi MJ et al. (2012) Ten modifiable health risk factors are linked to more than one-fifth of employer-employee health care spending. Health Aff (Millwood) 31, 2474-2484.

9. Person AL, Colby SE, Bulova JA et al. (2010) Barriers to participation in a worksite wellness program. Nutr Res Pract 4, 149-154.

10. Goetzel RZ \& Pronk NP (2010) Worksite health promotion how much do we really know about what works? Am J Prev Med 38, 2 Suppl., S223-S225.

11. Soler R, Leeks K, Razi S et al. (2010) A systematic review of selected interventions for worksite health promotion. The assessment of health risks with feedback. Am J Prev Med 38, 2 Suppl., S237-S262.

12. Mhurchu CN, Aston L \& Jebb S (2010) Effects of worksite health promotion interventions on employee diets: a systematic review. BMC Public Health 10, 62.

13. Sorensen G, Linnan L \& Hunt MK (2004) Worksite-based research and initiatives to increase fruit and vegetable consumption. Prev Med 39, 94-100.

14. Kolodinsky J \& Pelch L (1997) Factors influencing the decision to join a community supported agriculture (CSA) farm. J Sustain Agric 10, 129-141.

15. DeMuth S (2008) 1993 Community supported agriculture (CSA): an annotated bibliography and resource guide. http:// www.nal.usda.gov/afsic/pubs/csa/at93-02.shtml (accessed March 2012).

16. Oberholtzer L (2004) Community supported agriculture in the mid-Atlantic region: results of a shareholder survey and farmer interviews. http://www.smallfarmsuccess.info/CSA_ Report.pdf (accessed January 2011).

17. Cone CA \& Kakaliouras A (1995) Community supported agriculture: building moral community or an alternative consumer choice. Cult Agric 15, 28-31.

18. Lass D, Stevenson GW, Hendrickson J et al. (2003) CSA across the nation: findings from the 1999 CSA survey. http:// www.cias.wisc.edu/wp-content/uploads/2008/07/csaacross. pdf (accessed January 2011).

19. Cone CA \& Myhre A (2000) Community-supported agriculture; a sustainable alternative to industrial agriculture? Hum Organ 59, 187-197.

20. Pronk N, Lowry M, Maciosek M et al. (2011) The association between health assessment-derived summary health scores and health care costs. J Occup Environ Med 53, 872-878.

21. Pronk N, Katz A, Gallagher J et al. (2011) Adherence to optimal lifestyle behaviors is related to emotional health indicators among employees. Popul Health Manag 14, 59-67.

22. Pronk N, Lowry M, Kottke T et al. (2010) The association between optimal lifestyle adherence and short-term 
incidence of chronic conditions among employees. Popul Health Manag 13, 289-295.

23. Pronk NP, Tan AW \& O'Connor P (1999) Obesity, fitness, willingness to communicate and health care costs. Med Sci Sports Exerc 31, 1535-1543.

24. Cade J, Thompson R, Burley V et al. (2002) Development, validation and utilisation of food-frequency questionnaires a review. Public Health Nutr 5, 567-587.

25. Subar AF, Thompson FE, Kipnis V et al. (2001) Comparative validation of the Block, Willett, and National Cancer Institute food frequency questionnaires: the Eating at America's Table study. Am J Epidemiol 154, 1089-1099.

26. Block G, Thompson FE, Hartman AM et al. (1992) Comparison of two dietary questionnaires validated against multiple dietary records collected during a 1-year period. J Am Diet Assoc 92, 686-693.

27. Block G, Hartman AM \& Naughton D (1990) A reduced dietary questionnaire: development and validation. Epidemiology $\mathbf{1}$, 58-64.

28. Kant AK (2000) A prospective study of diet quality and mortality in women. JAMA 283, 2109-2115.

29. Goland C (2002) Community supported agriculture, food consumption patterns, and member commitment. Cult Agric 24, 14-25.

30. Schnell SM (2007) Food with a farmer's face: community supported agriculture in the United States. Geogr Rev 97, 550-564.

31. Landis B, Smith TE, Lairson M et al. (2010) Communitysupported agriculture in the Research Triangle region of North Carolina: demographics and effects of membership on household food supply and diet. J Hunger Environ Nutr 5, 70-84.

32. Brehm JM (2008) Motivations for participating in community-supported agriculture and their relationship with community attachment and social capital. Southern Rural Sociol 23, 94-115.

33. Andreatta S, Rhyne M \& Dery N (2008) Lessons learned from advocating CSAs for low-income and food insecure households. Southern Rural Sociol 23, 116-148.

34. Russell WS (2008) The adaptive consumer: shifting attitudes, behavior change and CSA membership renewal. Renew Agric Food Syst 23, 136-148.

35. MacMillan Uribe AL, Winham DM \& Wharton CM (2012) Community supported agriculture membership in Arizona: an exploratory study of food and sustainability behaviours. Appetite 59, 431-436.

36. Lang KB (2005) Expanding our understanding of community supported agriculture (CSA): an examination of member satisfaction. J Sustain Agric 26, 61-79.

37. Perez J, Allen P \& Brown M (2003) Community supported agriculture on the central coast: the CSA member experience. http://escholarship.org/uc/item/5wh3z9jg (accessed January 2011).

38. Jekanowski MD (2000) Consumers' willingness to purchase locally produced agricultural products: an analysis of an Indiana survey. Agric Resour Econ Rev 29, 43-53.

39. Quandt SA, Dupuis J, Fish C et al. (2013) Feasibility of using a community-supported agriculture program to improve fruit and vegetable inventories and consumption in an underresourced urban community. Prev Chronic Dis 10, E136.

40. O'Hara S \& Stagl S (2001) Global food markets and their local alternatives: a socio-ecological economic perspective. Popul Environ 22, 533-554.

41. Conner DS (2003) Community supported agriculture pricing and promotion strategies: lessons from two Ithaca, NY area farms. http://dyson.cornell.edu/outreach/extensionpdf/2003/ Cornell_AEM_eb0307.pdf (accessed January 2012).

42. Bougherara D (2009) Buy local, pollute less: what drives households to join a community supported farm? Ecol Econ 68, 1488-1495.

43. McFadden S (2012) Community farms in the 21st century: poised for another wave of growth? http://newfarm.rodale institute.org/features/0104/csa-history/part1.shtml (accessed February 2012).

44. Farnsworth RL, Thompson S, Drury K et al. (1996) Community supported agriculture: filling a niche market. J Food Distrib Res 27, 90-98.

45. Cooley J \& Lass D (1998) Consumer benefits from community supported agriculture membership. Rev Agric Econ 20, 227-237.

46. Fulkerson JA, Larson N \& Horning M (2014) A review of associations between family or shared meal frequency and dietary and weight status outcomes across the lifespan. J Nutr Educ Behav 46, 2-19.

47. Kant AK \& Graubard BI (2004) Eating out in America, 1987-2000: trends and nutritional correlates. Prev Med 38, 243-249.

48. McCrory MA, Fuss PJ, Hays NP et al. (1999) Overeating in America: association between restaurant food consumption and body fatness in healthy adult men and women ages 19 to 80 . Obes Res 7, 564-571.

49. French SA, Harnack L \& Jeffery RW (2000) Fast food restaurant use among women in the Pound of Prevention study: dietary, behavioral and demographic correlates. Int $J$ Obes Relat Metab Disord 24, 1353-1359.

50. Lachat C, Nago E \& Verstraeten R (2012) Eating out of home and its association with dietary intake: a systematic review of the evidence. Obes Rev 13, 329-346.

51. Gorber SC, Tremblay M, Moher D et al. (2007) A comparison of direct vs. self-report measures for assessing height, weight and body mass index: a systematic review. Obes Rev 8, 307-326. 